\title{
Quando o funk ostentação performa (re)existência: reflexões polissêmicas sobre contextos fronteiriços e experiências bastardizadas ${ }^{1}$
}

\author{
Aline da Silva Borges Rezende \\ Mestre em Comunicação e Práticas \\ de Consumo pela Escola Superior de \\ Propaganda e Marketing - ESPM/SP. \\ Participa do Grupo de Trabalho Infâncias \\ e Juventudes: cultura, comunicação e \\ política, do Conselho Latino-Americano \\ de Ciências Sociais (Clacso). Integra o \\ Grupo de Pesquisa Juvenália - Culturas \\ juvenis: comunicação, imagem, política \\ e consumo, vinculado ao CNPq no \\ Brasil. \\ E-mail: alinesbrezende@yahoo.com.br
}

\begin{abstract}
Resumo: Este artigo busca problematizar e refletir sobre a noção de resistência na contemporaneidade, tendo em vista os circuitos culturais e contextos específicos de recepção do gênero musical do funk ostentação. Interessa-nos, neste percurso, explorar os agenciamentos e as potenciais formas de resistência articuladas pelos jovens periféricos que protagonizam esse circuito musical, bem como os modos de (re)existência mobilizados a partir do consumo das narrativas midiáticas da ostentação entre um grupo de crianças, moradoras da maior favela sobre palafitas do país. Valendo-se dos aportes teóricos dos estudos culturais, em confluência com as categorias conceituais de culturas bastardas, narrativas midiáticas e performatividade, corroboramos a construção de uma abordagem polissêmica sobre o fator resistência, sobretudo no tocante às manifestações do popular-periférico contemporâneo.
\end{abstract}

Palavras-chave: Resistência; Consumo; Narrativas Midiáticas; Funk Ostentação; Criança.

When the Ostentation Funk perform (re)existence: polysemic reflections about frontier contexts and bastards experiences

Abstract: This article seeks to discuss and reflect on the notion of resistance
in contemporary times, in view of the cultural circuits and specific contexts of
reception of the ostentation funk musical genre. We are interested, in this
course, in exploring the funding and potential forms of resistance articulated by
young peripheral people of this music circuit, as well as the ways of (re)existence
developed from the consumption of media narratives of ostentation among
a group of children, residents of the largest slum built on stilts in the country.
Using the theoretical foundations of cultural studies, along with the conceptual
categories of culture bastards, media narratives and performativity, we intent
to contribute for the development of a broad approach on the resistance factor,
especially regarding manifestations of the contemporary popular-peripheral.

Keywords: Resistance; Consumption; Media Narratives; Ostentation Funk; Child.

\footnotetext{
${ }^{1}$ Este artigo é uma versão modificada e ampliada das reflexões apresentadas no GT Comunicação, consumo e novos fluxos políticos: ativismos, cosmopolitismos, práticas contrahegemônicas, do Congresso Internacional de Comunicação e Consumo - Comunicon 2016.
} 


\section{Introdução}

A reflexão delineada neste artigo parte das discussões que se desdobram da pesquisa de mestrado desenvolvida no Programa de Pós-Graduação em Comunicação e Práticas do Consumo (PPGCOM) da ESPM de São Paulo, cujo objetivo consistiu em investigar os usos e os modos de apropriação das narrativas midiáticas do funk ostentação entre um grupo de crianças de 6 a 12 anos de idade, moradoras da maior favela sobre palafitas do Brasil, a saber, o Dique da Vila Gilda, em Santos, município litorâneo de São Paulo.

Ao explorar os circuitos culturais e sociais que engendram esse gênero musical, presente no cotidiano dessas infâncias, observamos que suas narrativas vêm ao encontro de um período de intensas transformações sociais, políticas e econômicas, vivenciadas tempos atrás no país, que contribuíram para a inserção e a projeção da periferia nos campos midiáticos. No entanto, a construção narrativa e estética da vertente da ostentação é atravessada por elementos dissensuais e, até mesmo, contraditórios, uma vez que nas letras e videoclipes do funk ostentação o periférico é projetado e a periferia transborda seus limites territoriais contando, justamente, com a retórica distintiva das elites sociais, que sempre lhe puniu e subjugou. À vista disso, problematizamos: quais são os sentidos e as ressonâncias dessa ambivalência que enseja as narrativas e estéticas do funk ostentação? Seria este, então, mais um modo de sujeição e alienação dos atores sociais da periferia nas teias de dominação ou do hegemônico/mainstream?

Ao tomar este plano contextual pelas lentes analíticas do conceito de culturas bastardas, do teórico colombiano Omar Rincón (2015a, 2015b), defendemos que a ambivalência mobilizada pelos sujeitos periféricos desse circuito musical não configura, necessariamente, a mera reprodução dos estilos de vida elitista, tampouco o assujeitamento da periferia às lógicas de dominação, social e midiática. Temos, na verdade, que tal ambivalência e bastardia registram uma iniciativa potencial de resistência do popular-periférico contemporâneo. Porém, a compreensão do fator resistência delineado nesta reflexão não se restringe ao prisma defensivo e de enfrentamento, mas se apoia nos aportes teóricos dos estudos culturais (ESCOSTEGUY, 2010) e das reflexões de Certeau (1998), cujas proposições reivindicam o aspecto de negociação, as astúcias e as táticas que integram esse campo de disputas e conflitos que é a cultural.

Por isso, pensar a condição polissêmica de resistência é fundamental nesta jornada reflexiva, sendo este, portanto, o nosso ponto de partida de diálogo. Da compreensão conceitual que nos permite vislumbrar o circuito musical da ostentação para além das dicotomias entre dominantes e dominados, iremos explorar alguns aspectos desse movimento cultural protagonizado pelos jovens da periferia, a fim de identificar e analisar as possibilidades de resistência que se esboçam em suas estéticas audiovisuais.

Em último momento, compartilhamos um relato de campo obtido por meio do método de observação participante, realizado com o grupo de crianças que integram a pesquisa referida. Na ocasião, constatou-se que nos processos de apropriação das narrativas midiáticas do funk ostentação existe um jogo mimético em questão, cuja reverberação se dá a partir da performatividade (WULF, 2006) das letras e danças dessa vertente musical. No bojo dessa dinâmica de apropriação, a ambivalência do funk ostentação se revela em um duplo sentido semântico: como forma de (re)existência e resistência em meio às situações de adversidade e precariedade vivenciadas pelas crianças.

\section{Resistência: um conceito em negociação}

Alcançar um rigor conceitual sobre o termo resistência nos parece uma tarefa altamente sinuosa, haja vista a complexidade incutida em seus desdobramentos 
${ }^{1}$ Definições obtidas nos dicionários Michaelis, Priberam e Aurélio.

${ }^{2}$ Campo de estudos originado em meados da década de 1950, na Inglaterra, em um período de pósguerra de profundas transformações sociais (CEVASCO, 2003). Anos depois, em 1964, os Estudos Culturais conquistaram sua legitimação acadêmica a partir da criação do Centre for Contemporary Cultural Studies (CCCS), na Universidade de Birmigham. semânticos, que extrapolam enquadramentos fixos e imutáveis. Em um breve exercício de pesquisa em registros de dicionários ${ }^{1}$, é possível observar a amplitude de seus significados, revelados em sinônimos como: a) oposição; b) causa que contraria a ação de uma força; c) não aceitação da opressão; d) não ceder; e) defender-se; entre outros.

O efeito polissêmico de resistência se dá, justamente, por um fator singular de sua concepção, que diz respeito à dinamicidade das relações em sociedade, cada vez mais atravessadas por fluxos culturais, sociais, políticos, econômicos e identitários. Não por acaso, João Freire Filho (2007), numa perspectiva crítica, atribui à definição um sentido "camaleônico", por fazer-se como lente analítica e relacional que aporta ações coletivas e individuais, totalmente subversivas ou mais prosaicas e sutis do dia a dia.

Essas nuances coadunam, efetivamente, com as perspectivas teóricas delineadas por Raymond Williams, Eduard Thompson, Stuart Hall e outros pensadores que integram as reflexões seminais dos Estudos Culturais britânicos², cuja concepção sobre o campo cultural como espaço de lutas e tensões, em constante negociação, acaba por revelar ações potenciais de resistência, entendida como fator que expressa autonomia perante as ideias hegemônicas (CUCHE, 2002; ESCOSTEGUY, 2010). Ao lançar uma moldura conceitual que extingue as hierarquias culturais e concebe a cultura no âmago das relações sociais, essa corrente teórica sucumbe à visão reducionista de que exista somente submissão e alienação entre as classes menos abastadas da sociedade. Pelo contrário: sendo a cultura um lugar profícuo de interações, os atores sociais, inclusive das frentes populares, tornamse sujeitos de agência, que intervém, questionam, reivindicam e se opõem às estruturas determinantes da sociedade (ESCOSTEGUY, 2010).

É nessa linha de pensamento que as reflexões de Michel de Certeau (1998) dialogam com este plano teórico, à medida que concebe a experiência cotidiana como espaço de produção sociocultural, onde se proliferam "mecanismos de fugas" e possibilidades de desvios de padrões normativos e imposições sociais. Essas operações constituem as maneiras de fazer do homem ordinário, isto é, as táticas ou manobras das classes populares de subverter ou "tirar partido do forte", aludindo a ideia de resistência, ação que configura, por fim, a "politização das práticas cotidianas" (CERTEAU, 1998: 45).

Para João Freire Filho (2007: 21), essas duas reflexões objetivam, em essência:

esmiuçar (por meio de análises textuais e abordagens etnográficas) de que maneiras os recursos culturais funcionam tanto para forjar a aceitação do status quo e a dominação social quanto para habilitar e encorajar os estratos subordinados a resistir à opressão e a contestar ideologias e estruturas de poder conservadoras.

Dos sentidos de resistência sumarizados nessa discussão, é oportuno enfatizar que as chaves de leitura para a sua compreensão recaem, sobremaneira, em iniciativas subversoras e de rompimento do popular com as forças hegemônicas. No entanto, cabe-nos problematizar essa aferição posto que cada vez mais nos deparamos com iniciativas ambivalentes e de trânsito intermitente entre núcleos hegemônicos e contra hegemônicos, constituintes do que Rocha, Silva e Pereira (2015) denominam como cenas pós-periféricas ${ }^{3}$. Então, seria possível falar de resistência em contextos cuja ambiguidade e movimentação intersticial extrapola a condição de ruptura ou recusa da hegemonia?

Valendo-se ainda da linha de pensamento dos Estudos Culturais e de Certeau, uma reflexão possível para essa indagação pode ser delineada tendo em vista a palavra negociação, aspecto pujante que caracteriza esse campo de batalhas e conflitos

\footnotetext{
${ }^{3}$ Segundo as autoras, "Pós-periférico não supõe a inexistência ou a superação de desigualdades e hierarquias, mas surge como categoria que busca ampliar e pensar as situações de imbricamento (para o bem e para o mal) de práticas e imaginários, não pela via territorial, mas pela via simbólica" (ROCHA; SILVA; PEREIRA, 2015: 101).
} 
em que consiste a cultura. Dessa forma, o fator resistência é compreendido, também, como uma iniciativa inquiridora das estruturas condicionantes da sociedade, sem que seja operante uma ruptura ou uma ação contra hegemônica (ESCOSTEGUY, 2010).

Este retrato contextual parece figurar alguns movimentos culturais protagonizados pela periferia na contemporaneidade, a exemplo do circuito musical do funk ostentação, que assume um outro caráter evocativo do periférico por meio de uma atuação fronteiriça e bastardizada (RINCÓN, 2015a), que combina forças hegemônicas em composições estéticas dissensuais. No empenho de levantar algumas pistas para refletir sobre estes outros sentidos de resistência, iremos analisar os aspectos que constituem este gênero musical, sobretudo no que toca à construção narrativa e às suas expressões audiovisuais.

\section{A resistência do popular-periférico-bastardizado do funk ostentação}

Ao precipitar um olhar sobre os contextos pós-periféricos da contemporaneidade, somos desafiados a pensar sobre uma outra dimensão de resistência, que foge aos moldes deterministas e verificadores que refutam toda e qualquer penetração hegemônica. Trata-se, nesta linha de raciocínio, de compreender o fator resistência não apenas por um prisma defensivo dos oprimidos e fracos perante os dominantes, mas de uma ação questionadora, de negociação entre seus atores sociais.

Essa perspectiva corrobora ao entendimento de novas formas de politização e manifestação cultural do popular que são atravessadas, consubstancialmente, pelas narrativas midiáticas e do entretenimento (MARTÍN-BARBERO, 2013; RINCÓN, 2015a). Tal configuração não determina, necessariamente, o total assujeitamento e submissão nas teias de dominação ou do hegemônico, mas caracteriza o que Omar Rincón (2015a, 2015b) denomina como exercício de uma cidadania comunicativa, cuja potencialidade incide na criação de maneiras pop-

${ }^{4}$ Segundo Rincón (2015b: 196, tradução nossa), o sentido pop-lítico diz respeito à um modo de conceber a política articulada às formas de entretenimento, que configura, também, um modo de reivindicação do sujeito popular de estar em cena e participar das tramas midiáticas, preenchendo as telas com a diversidade de rostos e falas, para, então, "modificar o destino comunicativo do mainstream cool industrial e das tecnorredes para fazê-las no modo de cada comunidade". Nesta linha de pensamento, " $A$ consciência não é política somente quando se refere à classe, ou à pobreza, à marginalidade ou imperialismo; $a$ consciência política também existe nas estéticas, narrativas, formatos e modos de interpelação" (RINCÓN, 2015b: 192, tradução nossa). líticas ${ }^{4}$ de existir e de projetar aqueles que, historicamente, foram relegados à invisibilidade ou à marginalidade das dinâmicas sociais e comunicacionais.

Aliás, convém ressaltar que o sentido de "popular" partilhado nessa acepção excede a visão de uma autenticidade folclórica e de determinismos econômicos ou de classe. Mas conflui, sinergicamente, com a ideia de experiência bastarda do popular postulada por Rincón (2015a), cuja essência consiste em um modo ilegítimo, ambivalente e impuro de existência cultural. Nas palavras do autor:

\begin{abstract}
O popular bastardizado é um quilombo [...] de tudo: autenticidade, resistências, submissões, cumplicidades, inovações e aberrações [...] A bastardização popular é, então, isso que joga entre a cultura mainstream que se nutre do inglês, do made in USA e a hierarquia do cool (MARTEL, 2011) mas também bebe e goza com os corpos, as músicas e as telenovelas. (Ibid.: 33, tradução nossa).
\end{abstract}

Para Rincón, o popular bastardo se funda em uma iniciativa análoga à constituição tradicional da família, ou seja: só tem a certeza da origem materna - neste caso, a matriz cultural local -, e a dubiedade e incerteza de ser filho de muitos pais - as referências culturais do povo, do subalterno, do excluído, do artístico, do mainstream (MARTEL, 2012), do tecnológico, do pornográfico, entre outros. É justamente por vias dessa existência bastardizada que as expressões do funk ostentação se ancoram e nos permitem enxergar esses outros sentidos de resistência, à medida que seus atores sociais bebem e negociam com forças hegemônicas e heterogêneas para enaltecer o periférico e abalar, efetivamente, as dimensões simbólicas e as lógicas condicionantes das estruturas sociais. Para levar a cabo esta reflexão, cabe-nos delinear a trajetória desse gênero musical. 
${ }^{5}$ Criado no ano de 2005 por três jovens profissionais da área de tecnologia e, posteriormente, adquirida em 2006 pela gigante empresa multinacional Google, o YouTube tem por finalidade permitir aos seus usuários produzir, publicar, assistir e compartilhar vídeos na rede, que podem ser visualizados por qualquer pessoa no mundo inteiro.

${ }^{6}$ Wellington França, o MC Boy do Charmes, é considerado um dos precursores do estilo ostentação (FUNK..., 2012).

${ }^{7}$ A produtora Kondzilla foi a pioneira da estética da ostentação no circuito do funk brasileiro.

${ }^{8} \mathrm{O}$ documentário foi o primeiro a repercutir sobre a cena musical e a resgatar suas origens com os principais artistas e produtores de funk. Disponível em: <https://www.youtube.com/ watch?v=8M3CRYQJMfM>. Acesso em: 10/03/2017.

${ }^{9} \mathrm{~A}$ esse respeito, o teórico e economista Marcio Pochmann (2011: 15) argumenta que, neste período, a dinâmica expansionista de produção - que contribuiu para a formação de novos postos de trabalho - articulada à implantação e reordenação de políticas públicas voltadas à seguridade e assistência social, contribuíram para "estabelecer um novo padrão de mudanças sociais no Brasil". Nesse contexto, destacam-se a criação de novas políticas de enfrentamento à pobreza; programas sociais com vistas à moradia e à concessão de crédito; o aumento do poder aquisitivo da população; e, consequentemente, o crescimento das práticas de consumo. Porém, é oportuno sublinhar que, na atual conjuntura brasileira, muitos mecanismos sociais conquistados nos últimos anos vêm sofrendo retrocessos e estão comprometidos, sobretudo por conta dos escândalos de corrupção e instabilidade política instaurada pelo impeachment da ex-presidente Dilma Rousseff.
Em linhas gerais, o funk ostentação nasce em 2008 nas periferias da região metropolitana de São Paulo e da Baixada Santista, Litoral Sul Paulista, sendo amplamente difundido pelo país a partir de produções audiovisuais, veiculadas no canal de compartilhamento de vídeos on-line YouTube ${ }^{5}$. A notoriedade do circuito musical da ostentação ocorre anos depois, em 2011, com o lançamento do primeiro videoclipe dessa vertente do funk, protagonizado pela música "Megane", do MC Boy do Charmes $^{6}$, produzido por Konrad Dantas, idealizador da produtora Kondzilla". Com este vídeo, o funk brasileiro iniciou uma nova fase de sua estética audiovisual, cuja predominância imagética incide nas expressões que remetem ao consumo, ao capitalismo em seus fluxos supérfluos e excessivos, à projeção e distinção social na periferia. Daí, então, surgiu a denominação "ostentação", promulgada pela própria imprensa brasileira para se referir a essa onda do funk (FUNK..., 2012).

Com forte influência dos rappers norte-americanos, este gênero musical celebra em suas canções o imperativo do consumo de luxo, contemplado em cenários com carros e motos importados, roupas de marca, acessórios de ouro, bebidas, baladas, além das experiências sexuais atravessadas, fundamentalmente, por um viés patriarcal e machista, cuja figura feminina é, por vezes, considerada como outro objeto de ostentação. No entanto, tais experiências destoam do convencional ao serem protagonizadas por jovens de origem humilde e periférica da cidade, que tiveram suas vidas modificadas pela carreira musical (PEREIRA, 2015). Dessa maneira, o funk ostentação se revela como um movimento cultural que bebe da potência comunicativa dos epicentros midiáticos, a exemplo dos meios digitais e das estéticas do entretenimento, e que busca tensionar as barreiras sociais e territoriais da periferia, valendo-se, paradoxalmente, da presença excessiva dos signos que lhe subjugam em sociedade (ROCHA; SILVA; PEREIRA, 2015).

Endossando esse assunto, é oportuno sublinhar que, no bojo das narrativas midiáticas do funk ostentação, o consumo se vincula a um sentido de mediação, sendo reconhecido pelos atores sociais periféricos como uma forma possível de inclusão social, cujo caráter simbólico incutido em suas práticas promove novas maneiras de relacionar-se com o outro, de pertencer à sociedade e construir identidades possíveis (BACCEGA, 2014). A esse respeito, os MC da ostentação argumentam em entrevista ao documentário Funk OȘtentação (FUNK..., 2012) também produzido pela Kondzilla, que as músicas e videoclipes dessa vertente do funk apresentam "o poder da periferia", que também "pode e, sobretudo, tem o direito de consumir roupas e acessórios 'exclusivos'”, isto é, de grifes nacionais e internacionais. Os artistas ainda justificam que esse outro caráter evocativo da periferia, performatizado em suas produções, vem ao encontro de um período de intensas transformações sociais, culturais, políticas e econômicas do país, vivenciadas, com ênfase, entre os anos 2004 e 2011, durante as gestões do Governo Lula e a primeira administração de Dilma Rousseff ${ }^{9}$, que possibilitaram a inserção das práticas de consumo no cotidiano de muitos jovens da periferia.

À vista dessas acepções, partilhamos dos pensamentos de Alexandre Barbosa Pereira (2015) quando enfatiza que este circuito musical apresenta uma proposta estética, social e cultural potencialmente transgressora, pois os MC da ostentação se apropriam designos restritos, historicamente, a uma elite social e predominantemente branca, mas atribuem um outro sentido a este universo simbólico a partir de suas experiências na periferia, não sendo, somente, uma mera reprodução dos valores e estilos de vida das classes abastadas. Nessa linha de compreensão, o autor esclarece que a ostentação, singularidade que enseja o nome e as narrativas deste gênero musical, configura-se como um modo particular de a juventude periférica criar a periferia que inexiste nas telas da televisão, e, por vezes, na própria realidade: 
maioria da população brasileira, os funkeiros paulistas criavam também um mundo de luxo no qual eles poderiam imaginar-se como parte e mesmo exibirse como protagonistas. (PEREIRA, 2015: 7-8).

O relato de campo tecido por Pereira (2015) nos aponta para a potência criativa da imaginação que é celebrada nas canções e nos videoclipes do funk ostentação. Com efeito, o luxo ostentado nas produções musicais diz respeito a uma realidade mais imaginada pelos MC do que verdadeiramente "real", embora alguns desses artistas consigam ter acesso efetivo ao mundo de consumo que celebram nas performances audiovisuais. Mas é relevante, como destaca o autor, o fato de os funkeiros da ostentação se assumirem em condição de protagonismo, ainda que atuando em um universo ficcional.

Outro ponto significativo dessa reflexão se refere ao consumo imaginário mediado por outras experiências estéticas construídas pelas narrativas midiáticas do entretenimento, a exemplo da telenovela. Esse elemento estabelece uma conexão direta com os pensamentos de Edgar Morin (2002) sobre o profícuo terreno das participações televisuais, cuja membrana translúcida da tela é o que aproxima e isola; faz do globo ocular a porta de entrada para outros mundos possíveis e imaginários. Dessa forma, "os sucos que penetram através das membranas televisuais purgam e irrigam simultaneamente a personalidade e a própria vida do homem moderno" (MORIN, 2002: 72). Em consonância com essa acepção, entendemos que as produções dos jovens MC da ostentação são moldadas a partir do consumo imaginário de cenários ostensivamente luxuosos, que se integram à experiência marginal da periferia, construindo uma outra narrativa, quase friccional.

Não obstante a essa discussão, Felipe Trotta (2014) nos propõe uma outra possibilidade de compreensão sobre a ostentação que vem ao encontro das dimensões exploradas por Pereira. De acordo com Trotta (2014), a ostentação se revela em dupla função: em primeiro plano, como instrumento de afirmação e conquista dos atores sociais da periferia em novas posições e espaços na sociedade que, até então, Ihes eram privados; e, em segundo, como atribuição de um caráter provocativo e irônico em meio à "histórica negativização do popular".

Assim, o autor advoga que:

\footnotetext{
"Ostentar", segundo o Dicionário Houaiss, significa "exibir algo a outrem de modo intencionalmente hostil; estampar, pavonear, vangloriar". O "ostentador" é aquele "que demonstra prepotência ou vaidade". De modo bastante direto, os MCs do funk ostentação direcionam essa hostilidade prepotente aos setores de maior poder aquisitivo da população, utilizando agressivamente os mesmos elementos que sempre desqualificaram os "pobres". Se o problema é a falta de bens materiais, o funk ostentação responde com excesso deles, se é a falta de dinheiro para comprar bens simbólicos, a vertente ostentatória exibe a abundância. (TROTTA, 2014: 11).
}

Localiza-se, nestas reflexões, o fator resistência que se ancora na perspectiva de negociação, delineada na primeira parte dessa argumentação. Com efeito, o popular-periférico-bastardizado que protagoniza esse circuito musical encontra na ação comunicativa e no consumo potentes artimanhas para "tirar partido do forte" e "jogar" com o mainstream, o hegemônico, o status quo que o abomina. Nesse contexto, recorremos a Certeau (1998: 47) para ilustrar que:

Sem cessar, o fraco deve tirar partido de forças que lhe são estranhas. Ele o consegue em momentos oportunos onde combina elementos heterogêneos [...], mas a sua síntese intelectual tem por forma não um discurso, mas a própria decisão, ato e maneira de aproveitar a "ocasião". 
${ }^{10}$ Gíria que denomina os espaços urbanos periféricos.

${ }^{11}$ A comunidade de palafitas do Dique da Vila Gilda está localizada no bairro Rádio Clube, na zona noroeste de Santos, cuja região é conhecida por ser o retrato inverso das áreas nobres da praia, uma vez que abriga a população mais humilde do munícipio, sendo conjurada, também, como espaço da violência e da criminalidade. Constituída por mais de 10 mil habitantes, que vivem em moradias improvisadas de madeira, perfiladas sobre uma extensão de manguezal poluído, a comunidade é reconhecida pelas autoridades locais como uma das maiores áreas de vulnerabilidade social do município, haja vista que não dispõe de condições estruturais básicas como saneamento, rede de esgoto e infraestrutura elétrica.

\footnotetext{
${ }^{12}$ É oportuno esclarecer que o entendimento conceitual de infância, defendido nesta argumentação, vem ao encontro das reflexões epistêmicas da sociologia da infância, concebendo-a como integrante das estruturas sociais, atravessada por categorias geracionais e constituída histórica e socialmente. Ao adotar o conceito no plural - infâncias - estamos considerando, também, os diferentes contextos socioculturais e suas implicações nas vivências cotidianas da criança.
}

\footnotetext{
${ }^{13}$ Estilo de dança performativa do funk, originada no Jardim do Romano, na zona leste de São Paulo. Para mais informações, ver: <https://goo.gl/ kUXqDe>. Acesso em: 4 abr. 2017.
}

Então, se não havia espaço para a ostentação do periférico no horário nobre da televisão, os MC roubaram a cena nos interstícios do campo midiático; se não eram vistos nas mansões das novelas, então construíram seus palácios na própria quebrada ${ }^{10}$; se eram mudos e invisíveis em decorrência a origem marginal, logo passaram a incomodar pela força orgástica dos bens materiais e do brilho reluzente de seus cordões de ouro.

Pela concepção oblíqua do periférico, que joga e se move entre os papéis de "dominantes" e "dominados", é que o funk ostentação registra seu potencial de resistência, em uma iniciativa provocativa, sarcástica, questionadora, que coloca a periferia no eixo das práticas de consumo, sem que o orgulho de pertencer a determinada condição marginal seja extinto. Contribuindo com esta reflexão, recorremos novamente a Pereira (2013: n.p.) para dizer que o funk ostentação:

não necessariamente se contrapõe ao hegemônico, na medida em que tenta se afirmar pelo consumo, mas provoca um desconforto, um ruído extremamente irritante para aqueles que se pautam por um discurso e uma prática de segregação dos que consideram como seus "outros".

A ambivalência discursiva configura, nesse contexto, uma forma de resistência do funk ostentação. Por corolário, as ressonâncias desse outro modo de resistir se fazem evidentes nos contextos de recepção da vertente da ostentação, especialmente no contexto que protagoniza a pesquisa que inspira esta argumentação. Ao acompanhar as experiências cotidianas de um grupo de crianças da comunidade do Dique da Vila Gilda, na cidade de Santos, em São Paulo, observamos a presença constante das músicas e danças do funk ostentação como meio de evasão da precariedade de vida e contestação em situações particulares. Sobre esse assunto, apresentamos, a seguir, um episódio de campo, fruto do exercício metodológico que compõe esse artigo.

\section{Quando o funk ostentação performa resistência... e (re)existência}

A experiência de campo aqui apresentada faz parte dos resultados da observação participante realizada com um grupo de crianças, entre 6 e 12 anos de idade, moradoras da maior favela sobre palafitas do Brasil ${ }^{11}$. Para investigar os usos e os modos de apropriação das narrativas midiáticas do funk ostentação entre os atores sociais infantis, acompanhamos a turma, por um ano e meio, durante os trajetos que faziam do beco das palafitas à instituição que as acolhem, bem como as interações feitas nesse espaço de pertencimento, localizado no bairro da comunidade.

Coadunando com o plano teórico-metodológico de observação com o registro em diário de campo, esta investigação contou com as ordens sensíveis do olhar e da escuta, faculdades cognitivas e perceptuais que, imbricadas, viabilizaram nossa entrada e participação no universo das infâncias ${ }^{12}$ que protagonizam a pesquisa. Inspirando-se nas reflexões de Sérgio Cardoso (1993: 348), realizamos o incessante exercício do "olhar feito indagação", cuja configuração defronta "limites, lacunas, divisões e alteridade". Em complemento ao impulso inquiridor do olhar, exercitamos também a escuta, espaço de trocas semânticas (OLIVEIRA, 2006), de significação elementar que possibilitou a construção de uma relação de confiança e reciprocidade com o grupo infantil.

Por meio da dimensão do sensível, mobilizada durante a interação com as crianças, é que auscultamos a forte presença das narrativas bastardas do funk ostentação entre as culturas infantis do beco. Com efeito, as batidas da ostentação eram evocadas, constantemente, por meio do batuque das mãos sobre toda e qualquer superfície do ambiente; do ritmo amplificado nos corpos infantis nas coreografias do passinho do romano ${ }^{13}$; dos gestos de "empoderamento" dos 
${ }^{14} \mathrm{Na}$ linguagem do funk ostentação, "nave" é sinônimo de carro de luxo.

${ }^{15}$ Expressão utilizada para caracterizar as meninas jovens dos videoclipes do funk ostentação.

${ }^{16}$ Segundo as crianças participantes do estudo, a banca do Nicolau é um camelô local, onde elas adquirem os DVD de videoclipes de funk ostentação, filmes, entre outros.

\footnotetext{
${ }^{17}$ Nesse estudo, retomamos o conceito de capital cultural à luz das reflexões da teórica latino-americana Roxana Morduchowicz (2004: 40, tradução nossa), cuja compreensão sobre capital cultural diz respeito à "capacidade de estruturar e relacionar os saberes que se têm. O capital cultural, portanto, é volume e estrutura. [...] Trata-se de estruturar os saberes adquiridos com os que se incorporam e se constroem diariamente".
}

braços que seguiam os embalos das rimas, e da impostação da voz que exclamava "a nave"14, "a novinha"15 e a "vida diferenciada em Guarujá".

De fato, o funk ostentação pode ser compreendido como um feito orgânico do cotidiano dessas infâncias, haja vista que, segundo as próprias crianças, o funk é o "som do beco", sonoridade incorporada à atmosfera da comunidade do Dique da Vila Gilda, como uma característica singular e inerente a este espaço urbano.

Em interlocução direta com essas proposições, é oportuno sublinhar que os registros relatados pelas crianças da escuta musical da vertente da ostentação decorrem, fundamentalmente, das experiências urbanas nos becos e nos bailes de comunidades. A onipresença desse gênero musical se dá por meio dos altofalantes dos comércios locais que revestem as paisagens sonoras da comunidade; nas coletâneas musicais de funk adquiridas na banca do $\mathrm{Nicolau}^{16}$, que preenchem as telas dos televisores e o som das moradias precárias; dos bailes de rua realizados semanalmente, onde o contato com as músicas ocorre tanto na participação física das crianças nas festas quanto na escuta indireta dos sons que atravessam as finas tábuas de madeirites de suas casas.

Assim, as narrativas bastardas do funk ostentação, no contexto específico de recepção explorado em pesquisa, atuam como articuladoras das experiências urbanas periféricas e de socialização das crianças na comunidade, corroborando, também, à construção identitária e à formação do capital cultural ${ }^{17}$ dos sujeitos infantis. A esse respeito, a pesquisadora Roxana Morduchowicz (2004) explica que as crianças recorrem, com frequência, às experiências de ouvintes e telespectadores para atuar em determinadas situações cotidianas, sobretudo em condições de alteridade com os adultos. A autora acredita que a constituição da agência infantil perpassa, fundamentalmente, pelo consumo midiático e pelo acesso a produtos culturais e bens simbólicos, enraizados em seus contextos sociais. A pesquisadora ainda ressalta que, aliada a outros agentes da sociedade, como a escola e a família, a apropriação das narrativas midiáticas possibilita a inserção e o compartilhamento de uma identidade cultural na infância. Nas palavras de Morduchowicz:

\begin{abstract}
Os meios de comunicação constroem mitos e histórias através das quais os indivíduos constituem uma cultura comum. Por meio de sua apropriação, nos inserimos nela. Os indivíduos que compartilham de uma mesma identidade cultural partilham de uma série de conceitos, imagens e ideias que thes permitem pensar, interpretar e sentir sobre o mundo de maneira mais ou menos igual (HALL, 1997). Os meios de comunicação participam da construção dessa identidade. Influenciam sobre nossa noção de gênero, sobre nosso sentido de classe, de raça, de nacionalidade, sobre quem somos perante "os outros" e quem são "eles". (MORDUCHOWICZ, 2003: 35, tradução nossa)
\end{abstract}

Não obstante esta reflexão, observamos, na vivência com as crianças, que as músicas e videoclipes de funk ostentação ensejam o contato do grupo infantil com outros modos de existência e práticas de consumo, haja vista que as narrativas desse gênero musical mobilizam imaginários diaspóricos da periferia - aquela que sonha, alcança, consome e ostenta. Essa potência imaginária das produções audiovisuais da vertente da ostentação, sumarizada no tópico anterior, reverbera nas falas infantis quando justificam que o conhecimento de marcas, acessórios e lugares, ora distantes do cotidiano das bordas da cidade, ocorrem justamente quando tomam contato com as músicas e videoclipes do funk ostentação, cuja essência bastarda conjuga o periférico no "entre" das zonas hegemônicas e contra hegemônicas.

Trata-se, portanto, não apenas de um consumo midiático que entorpece os sentidos ou corrobora integralmente à degradação das infâncias e juventudes, 
${ }^{18}$ A exemplo da matéria do jornal Notícias do Dia, de Florianópolis, que dá o veredicto em sua manchete: "Funk ostentação é a isca para menores ingressarem no tráfico de drogas em Florianópolis" (TORRES, 2013). como destacam algumas reportagens da grande imprensa ${ }^{18}$. O contato com as audiovisualidades da ostentação possibilita transpor e, por vezes, evadir, ainda que por vias imaginárias, a precariedade de vida; a exclusão geográfica e social; a experiência familiar fragmentada; a vivência entre as drogas e a violência; a fase infantil entre todos esses conflitos. Então, remontamos o duplo sentido semântico de (re)existência assumido nessa argumentação. Reexistir por meio das sonoridades do funk ostentação implica pensar tais narrativas como "um recurso para inovar a rotina diária e encantar a existência” (RINCÓN, 2006: 47, tradução nossa).

Essa chave explicativa contribui para pensar sobre os usos das narrativas midiáticas do funk ostentação, sobretudo no tocante aos agenciamentos infantis em situações cotidianas. Uma experiência singular vivida em campo conflui com essa discussão. $\mathrm{Na}$ ocasião, os atores sociais infantis se apropriaram das expressões geradas e veiculadas nas produções audiovisuais do funk ostentação, performando-as diante de seus pares e grupos de alteridade, caracterizando uma iniciativa de afirmação de um lugar de fala periférico e, ao mesmo tempo, de contestação e ironia:

Na tarde do dia 30 de dezembro de 2015, acompanhei as crianças em um evento de confraternização de Natal e fim de ano, promovido por voluntários de uma ONG da cidade, no espaço de acolhimento frequentado pelas crianças [...]. Além de muitos salgados e doces, às crianças foram oferecidas diversas atividades como maquiagens artísticas para meninos e meninas, brincadeiras e apresentações com palhaços. Enquanto grande parte das meninas aguardava ansiosamente na fila para pintar borboletas, flores e corações em seus rostos, os meninos voltaram sua atenção para a atividade de karaokê, iniciativa promovida por dois voluntários com violões, próximo ao extenso jardim da casa. A ideia era deixar a escolha das músicas e a cantoria sob a responsabilidade das crianças. $O$ momento foi oportuno para criar um verdadeiro baile funk, causando o pavor e espanto dos voluntários, que argumentavam "estas músicas não são para crianças!". Contrariando os esforços de argumentação dos voluntários, as crianças pegavam o microfone e cantavam as músicas que escutavam no beco. Dentre as que pude reconhecer, estavam: "Baile de favela", do MC João; "Ostentação fora do normal", do MC Daleste; "Megane", do MC Boy do Charmes, além de músicas que elas diziam ser de $\mathrm{MC}$ da própria comunidade e de artistas como Anitta e Ludmilla [...]. A grande atração da festa ficaria por conta de uma apresentação de ballet, realizada por um grupo de meninas do bairro da Ponta da Praia, local nobre da cidade. As crianças foram organizadas para assistir as bailarinas mirins no mesmo espaço onde haviam feito seu "baile funk", só que agora sentadas, um feito quase impossível para elas, que não suportam ficar muito tempo quietas, paradas. Ao começar a apresentação, a música clássica, em ritmo lento, e por vezes cantada em inglês, causava gargalhadas nas crianças. As meninas se encantavam com as roupas de fadas e as maquiagens das bailarinas, que "pareciam princesas", de acordo com X e Y. Mesmo com este encantamento, não demorou muito para que começasse uma inquietação geral entre o grupo de crianças. Na segunda música da apresentação, algumas crianças levantaram e, subitamente, começaram a cantar suas músicas de funk e dançar no passinho do romano. Voluntários corriam para tentar alcançar e tirar as crianças de cena, causando ainda mais o riso da plateia infantil. Mesmo com inúmeras repreensões dos voluntários, as crianças se esquivavam da mira deles, tomavam a frente das bailarinas e faziam ali seus passos marcantes e rimas da ostentação. Um cenário friccional se formava ali: crianças negras e descalças cantando e dançando funk, sobre o plano de fundo "cinderelesco" e delicado das bailarinas loiras e brancas. (Caderno de campo).

O relato de campo possibilita articular diversas reflexões sobre os usos dessa narrativa midiática no contexto infantil. Nos limites dessa reflexão, importanos atentar para o caráter performativo das expressões do funk ostentação manifestado pelas crianças com o canto das músicas e a dança do passinho do romano. Esse agir rítmico acentuado pela dimensão corporal aproxima-se da compreensão de mimese e performatividade da cultura, que consiste no "caráter da encenação e representação do agir, do imaginar, do falar e do comportar-se, 
tão fortemente ligados ao corpo" (WULF, 2006: 46-47). No tocante a esse ponto, convém esclarecer que o processo de mimese não se refere ao assujeitamento da criança à reprodução ou imitação integral do mundo adulto, mas trata-se do encontro entre o universo interior infantil e o mundo externo, no qual sempre é acrescida uma nova qualidade à apropriação mimética. Nessas condições:

Enquanto este exterior é transportado com os sentidos e a imaginação para o processo mimético na forma de imagens internas, corpos sonoros e mundos táteis, olfativos e palatáveis, surgem experiências vivas ligadas à iniludível corporalidade da criança. (GERBAUER; WULF, 2004: 156).

Por sua vez, a performatividade nos processos miméticos está intrinsecamente ligada à estética, ao lúdico, ao ritualístico e, sobretudo, ao corpo - cunhado social e culturalmente. Nas palavras de Wulf (2006: 49),

Performatividade aponta uma possibilidade que têm os seres humanos de assumir uma "posição excêntrica" (PLESSNER), isto é, de não apenas estarem em seu próprio corpo, mas de possuí-lo. Temos de nos projetar e atuar em diferentes encenações. Para podermos nos perceber, compreender e entender, encenamos; e nessas encenações e seus efeitos em outros seres humanos, assim como suas reações a nossas ações, nos descobrimos. Com base na plasticidade inerente ao corpo humano, o espectro de possíveis encenações e representações é grande. [...] A amplitude de variação do performativo nos diferentes campos de vida e atividades humanas tem estreita ligação com questões relativas às [sic] diferenciação social entre gêneros, gerações e as camadas sociais.

Sob essa lente analítica, delineamos a seguinte reflexão sobre a experiência de campo partilhada: a partir do consumo das narrativas bastardas do funk ostentação, inicia-se um processo mimético, cuja reverberação é evidenciada pelo canto e pelas danças realizadas pelos meninos e meninas. Ao mobilizar a potência corporal e a linguagem verbal que entoa as letras da ostentação para jogar e posicionar-se diante do elemento de alteridade, esse grupo infantil produz uma representação da periferia, resgatando, no momento da apresentação de ballet, uma de suas principais matrizes culturais, a saber, o funk brasileiro. Tratase, pois, de uma atitude de afirmação de suas origens periféricas e, por extensão, de uma ação potencial de resistência, entendida nessa situação como um modo contestatório e questionador das imposições figuradas pela apresentação de ballet e da atitude de repreensão dos voluntários e das freiras.

No bojo dessa questão, o consumo - imaginário e midiático - revela-se como um dos pontos de confluência entre a trajetória reflexiva sobre o circuito musical do funk ostentação e o contexto específico de recepção, singularizado pelas crianças da comunidade do Dique da Vila Gilda. Enquanto os MC mobilizam em suas canções e videoclipes uma ação negociada entre universos simbólicos distintos, configurando uma atitude inquiridora das estruturas sociais por meio do consumo imaginário de signos elitistas; as crianças, por sua vez, consomem esta narrativa midiática ambivalente, apropriando-se, por vezes, de suas expressões, para experimentar outros modos de ser e pertencer a universos distintos, isto é, de (re)existir em meio às condições de precariedade e pobreza. Por outro lado, o grupo infantil também se utiliza das danças e das letras da ostentação para afirmar um lugar de fala e origem periférica, aproximando-se, assim, de uma forma de resistência tática, que visa "burlar", aos seus modos lúdicos e inventivos, o que lhes foi imposto.

\section{Considerações finais}

Ao considerar a noção de resistência pela perspectiva da negociação, e não somente por vias de enfrentamento e oposição, ampliamos o entendimento sobre as manifestações do popular contemporâneo e suas outras formas de politizar, 
que se pautam, sobremaneira, pelas narrativas midiáticas, pelas estéticas do entretenimento, como também pelas práticas de consumo. Compartilhando da mesma visão, Pereira e Pontes (2016: 4-5) enfatizam que:

Nesta noção de negociação, reposicionam-se ou ressemantizam-se noções de resistência cultural vistas como puro enfrentamento ao hegemônico ou algo autônomo e revolucionário, para dar espaço a uma noção de resistência que se faz nas fímbrias, no cotidiano, nas apropriações inesperadas e não programadas.

Com efeito, a estética bastardizada do funk ostentação e sua irreverente forma de narrar o periférico que "ostenta" nos leva à concepção de uma outra lógica do agir político e, por corolário, de outros modos de resistência dos jovens das periferias que operam este circuito musical. A conjugação de universos simbólicos distintos apresenta-se como uma tática astuciosa, tomando por base as reflexões de Certeau (1998), de a juventude periférica alcançar a projeção e o reconhecimento, social e midiático. Endossando essa acepção, recorremos ao mesmo autor para dizer que "a tática não tem por lugar senão o do outro. E por isso deve jogar com o terreno que lhe é imposto tal como organiza a lei de uma força estranha" (Ibid.: 100).

Nessa mesma linha de raciocínio, encontramos, no contexto de recepção explorado, que as narrativas midiáticas do funk ostentação também se articulam como táticas, à medida que são mobilizadas como brechas para encantar e reinventar o cotidiano nas bordas da cidade. Mais uma vez, Morduchowicz (2004) nos auxilia para pensar sobre esse aspecto quando elucida que as manifestações populares e os produtos midiáticos - e aí se incluem as expressões musicais e audiovisuais do funk ostentação - ensejam espaços de significação e novas formas de sentido às identidades infantis, promovendo encontros, choques e rupturas com o universo adulto.

Por meio desse contato com os campos estéticos do funk ostentação, as crianças também constroem suas "artimanhas" para posicionar-se perante seus pares e os adultos. No relato de campo apresentado, observamos que, por meio de um processo mimético, o funk ostentação é apropriado e performatizado pelas crianças, a partir de suas linguagens infantis, como meio de afirmar suas origens periféricas e, de modo ambivalente, como possibilidade de ultrapassá-las; bem como para a socialização entre seus pares e grupos de alteridade.

Levando em consideração as virtudes apresentadas, acreditamos que pensar os contextos fronteiriços e experiências bastardizadas do popular contemporâneo, especialmente no que toca às manifestações culturais da periferia, demandam, sobremaneira, o rompimento com abordagens unilaterais, moralistas e engessadas em sistemas dicotômicos, haja vista que a ambivalência é a própria gramática cultural da experiência cotidiana.

\section{Referências}

BACCEGA, M. A. Comunicação e consumo. In: CITELLI, A. et al. (Orgs.). Dicionário de comunicação: escolas, teorias e autores. São Paulo: Contexto, 2014. p. 53-65.

BRUM, E. Os novos "vândalos" do Brasil. El País Brasil, São Paulo, 23 dez. 2013. Disponível em: <https://goo.gl/wYUXbs>. Acesso em: 27 out. 2017.

CARDOSO, S. O olhar do viajante. In: NOVAES, A. O olhar. São Paulo: Companhia das Letras, 1993. p. 347-360. 
CERTEAU, M. A invenção do cotidiano. Tradução Ephraim Ferreira Alves. 3. ed. Rio de Janeiro: Vozes, 1998.

CEVASCO, M. E. Dez lições sobre estudos culturais. São Paulo: Boitempo, 2003.

CUCHE, D. A noção de cultura nas ciências sociais. Tradução Viviane Ribeiro. 2. ed. Bauru: Edusc, 2002.

ESCOSTEGUY, A. C. D. Cartografias dos estudos culturais: uma versão latinoamericana. Belo Horizonte: Autêntica, 2010.

FREIRE FILHO, J. Reinvenções de resistência juvenil: os estudos culturais e as micropolíticas do cotidiano. Rio de Janeiro: Mauad X, 2007.

FUNK Ostentação - O Filme (COMPLETO) HD. Documentário. 36'31". Jonatan Monteiro. YouTube. 2012. Disponível em: <https://goo.gl/JjEGea>. Acesso em: 27 out. 2017.

GERBAUER, G.; WULF, C. Mimese na cultura: agir social, rituais e jogos, produções estéticas. Tradução Eduardo Triandopolis. São Paulo: Annablume, 2004.

MACHADO, L. Com dança de robô, "passinho do Romano" vira febre na periferia de SP. Folha de S. Paulo, São Paulo, 15 jun. 2014. Disponível em: <https://goo.gl/ WVtJZj>. Acesso em: 27 out. 2017.

MARTEL, F. Mainstream: a guerra global das mídias e das culturas. Tradução Clóvis Marques. Rio de Janeiro: Civilização Brasileira, 2012.

MARTÍN-BARBERO, J. Dos meios às mediações: comunicação, cultura e hegemonia. Tradução Ronald Polito e Sérgio Alcides. 7. ed. Rio de Janeiro: UFRJ, 2013.

MORDUCHOWICZ, R. El capital cultural de los jóvenes. Buenos Aires: FCE, 2004.

MORIN, E. Cultura de massas no século XX: neurose. Tradução Maura Ribeiro Sardinha. 9. ed. São Paulo: Forense Universitária, 2002. (Coleção $O$ espírito do tempo, v. 1).

OLIVEIRA, R. C. O trabalho do antropólogo. 2. ed. São Paulo: Unesp, 2006.

PEREIRA, A. B. Funk ostentação em São Paulo: imaginação, consumo e novas tecnologias da informação e da comunicação. Revista de Estudos Culturais, São Paulo, n. 1., 2015. Não paginado. Disponível em: <https://goo.gl/nBgZLy>. Acesso em: 27 out. 2017.

PEREIRA, S. L.; PONTES, E. V. Culturas juvenis, identidades e estilo de vida: o que é ser "alternativo" no Baixo Augusta/São Paulo? In: CONGRESSO INTERNACIONAL COMUNICAÇÃO E CONSUMO, 6., 2016, São Paulo. Anais... São Paulo: ESPM, 2016. p. 1-15. Disponível em: <https://goo.gl/sN2BAs>. Acesso em: 27 out. 2017.

POCHMANN, M. Políticas sociais e padrão de mudanças no Brasil durante o governo Lula. SER Social, Brasília, DF, v. 13, n. 28, p. 12-40, jan./jun. 2011. Disponível em: <https://goo.gl/JHgm1Q>. Acesso em: 27 out. 2017.

RINCÓN, O. Narrativas mediáticas: o cómo se cuenta la sociedad del entretenimiento. Barcelona: Gedisa, 2006.

- Lo popular en la comunicación: culturas bastardas + ciudadanías celebrities. In: AMADO, A.; RINCÓN, O. (Eds.). La comunicación en mutación: remix de discursos. Bogotá: Fundación Friedrich Ebert, 2015a. p. 23-42. 
. Lo pop-pular está de moda: sobre culturas bastardas y quilombos poplíticos. In: SAINTOUT, F.; VARELA, A.; BRUZZONE, D. (Orgs.). Voces abiertas de América Latina: comunicación, política y ciudadanía. Buenos Aires: Clacso, 2015b. p. 179-213.

ROCHA, R. M.; SILVA, J. C.; PEREIRA, S. L. Imaginários de uma outra diáspora: consumo, urbanidade e acontecimentos pós-periféricos. Revista Galáxia, São Paulo, n. 30, p. 99-111, dez. 2015. Disponível em: <https://goo.gl/YMg6ee>. Acesso em: 27 out. 2017.

TORRES, A. Funk ostentação é a isca para menores ingressarem no tráfico de drogas em Florianópolis. Notícias do Dia, Florianópolis, 29 out. 2013. Disponível em: <https://goo.gl/nTDwft>. Acesso em: 27 out. 2017.

TROTTA, F. C. A música que incomoda: o funk e o rolezinho. In: ENCONTRO ANUAL DA COMPÓS, 23., 2014, Belém. Anais... Belo Horizonte: Compós, 2014. p. 1-17. Disponível em: <https://goo.gl/pGHjDk>. Acesso em: 27 out. 2017.

WULF, C. Linguagem, imaginação e performatividade: novas perspectivas para a antropologia histórica. In: BAITELLO JÚNIOR, N. et al. (Orgs.). Os símbolos vivem mais que os homens: ensaios de comunicação, cultura e mídia. São Paulo: Annablume, 2006. p. 37-54. 